\title{
Impact of External Quality Assurance Practices on Higher Education Institutions in Tanzania: A Review Paper
}

\author{
Aloyce M. Nyamwesa ${ }^{1}$, Evelyne F. Magambo ${ }^{2 *}$ and Daniel Oduor Onyango ${ }^{3}$ \\ ${ }^{1}$ Department of ICT and Mathematics, College of Business Education, Mwanza, Tanzania \\ ${ }^{2}$ Department of Accountancy, College of Business Education, Mwanza, Tanzania \\ ${ }^{3}$ Department of Education Foundations, St. Augustine University of Tanzania, \\ *Corresponding Author-e.magambo@cbe.ac.tz
}

\begin{abstract}
For the past two decades, quality issues in higher education have attracted many scholars. While scholars are trying to answer the question whether quality assurance both internal and external has an impact on the operations and output from higher education institutions, there is evidence that quality is still a problem in Tanzania. This can be established by a series of deregistration of universities due to nonconformity. In February 2016 TCU revoked the earlier approval that established two private universities and in January 2020 it deregistered six universities and three campuses for quality issues. This study examined previous empirical literature on higher education in order to establish the impact of external quality assurance practice on operations and output of higher education institutions. It focused on creating understanding of EQA and its concepts, identifying benefits of EQA in HEls and determining ways of improving adherence to EQA. While focusing on impact of external quality assurance practices, this paper reviewed various literatures from previous studies published between 2010 and 2020 on the subject matter. Findings from the review suggest that external quality assurance has both positive and negative impacts on universities' internal operations. Some of the negative effects include increased cost of operations and the positive are increased enrolment, quality output and good internal quality assurance practice). It is therefore important that higher learning institutions adhere to External Quality Assurance and go beyond its requirements for better results. It is also recommended that External Quality assurance practices should align with globalization pace and that the government should extend support to private universities for maximized quality.
\end{abstract}

Keywords: Impact, Quality assurance, External quality assurance, University, Higher Education

\section{Introduction}

Higher Education Institutions (HEls) are established to offer service to its varying stakeholders. While these stakeholders range from students to regulators, the quality of service offered by Higher Education Institutions is important. The service quality level is relative to stakeholders' expectations. Higher Education Institutions (HEIs) have to ensure that they serve students and other stakeholders in a way that they are able to meet their expectations. With this regard, HEls in Tanzania have recently embarked on quality assurance approaches in delivering their services. These approaches are used in all processes undertaken by HEIs (Ryan, 2015).
Quality assurance in Higher education is divided into two types i.e. Internal Quality Assurance (IQA) and External Quality Assurance (EQA). Martin (2018) defines IQA as all processes that education institutions use to monitor teaching, learning environment, assessment procedures and other allied activities. She also defines EQA as the process of ensuring that assessment and IQA activities have been conducted in a consistent, safe and fair manner. This is carried out by the Regulatory Authority i.e. the government agency. Initially most governments established different bodies to oversee the quality of private universities which increased spontaneously yet with limited resources which made their quality assurance questionable. It 
was believed that government universities adhere to quality as they are governed by the state.

While Quality Higher Education is very important in the contemporary world, it is often regarded as the kind of education that gives students the knowledge and skills needed by the job market. Therefore, quality education should provide fit for purpose education.

For the past two decades, scholars have tried to answer the question whether quality assurance both internal and external has an impact on the operations and output from Higher Education Institutions. The aim of this paper is therefore to review literature on the impact of external assurance practices on Higher Education Institutions.

The quality problem in Higher Education also exists in Tanzania. It has been believed that quality is still a problem in the country especially with Private Universities. This can be established by a series of deregistration of private universities due to nonconformity. In February 2016 Tanzania Commission for Universities (TCU) revoked the earlier approval that established two private universities (Kolumbia, 2016). Furthermore, in January 2020 TCU deregistered six universities and three campuses for quality issues including human resources, funds and poor infrastructures (Peter, 2020).

The purpose of this paper therefore, is to review previous empirical literature on higher education in order to establish the impact of external quality assurance practice on operations and output of Higher Education Institutions in Tanzania. While Higher Education Institutions are churning out thousands of graduates every year, various stakeholders continue to question ability of some of these graduates. Governments spend trillions of money to fund Higher Education through loans to students in order to meet the cost of operation in universities. While governments spend a lot of money to finance quality assurance agencies, this study looks at whether the EQA practices help Higher Education Institutions to be effective.

It is expected that this review will help stakeholders in HEls and particularly external quality assurance bodies to establish a mechanism that will ease the implementation of EQA. Such will later improve the quality of Higher Education in Tanzania. From the review, stakeholders of quality in higher education will be able to identify their positions and act accordingly.

\section{Quality Assurance Concept}

The perception of quality assurance is very multidimensional and contextual. There exist a gap between the views of quality assurance professionals and academic staff on the concept of quality assurance (Smidt, 2015). The contextual gap on what is Quality Assurance is also noted by Ryan, (2015) where he noted that there is no agreed definition of QA. He further suggested a need to have a common framework for quality assurance model. This discrepancy calls for common understanding on what quality assurance means when it comes to higher education. It is therefore important to bridge the gap and have common understanding on various $Q A$ concepts as used in higher education management.

To ensure quality, the needs of different stakeholders are important. HEls have different stakeholders ranging from students to the society in general. Satisfying the needs of these stakeholders is crucial for sustainability. Establishing the satisfaction level of stakeholders requires feedback form them. Therefore feedback becomes an important component of quality assurance. Liu and Mattila (2015), highlights the importance of customer feedback in providing quality services and satisfying customers. They state that, customer feedback helps organizations establish performance gaps. When the gap is identified and measures for improvement are taken, continuous improvement is assured.

\section{Internal Quality Assurance}

Internal quality assurance includes all that an organization does internally so as to assure its customers of quality products or services. Martin (2018) defines IQA as all processes that education institutions use to monitor teaching, learning and assessment activities. Literally this means IQA is about how well Higher Education Institutions are discharging their duties of teaching, researching assessing and community service. Parri, (2006) defines IQA as internal policies and mechanisms of a $\mathrm{HEI}$ or program which ensures that the $\mathrm{HEI}$ is fulfilling its purposes and is in conformance/compliance with the standards that apply to Higher Education in general or to the profession or discipline in particular.

In his study, Okae-Adjei (2016) revealed that HEls lack the internal quality management systems that 
are strong enough for effective self-regulation of their operations when compared to practices. It should be noted that while universities and university colleges set pre-determined standards that they should conform with, effective selfregulation is important to ensure such conformance. The author further noted that HEls are not taking trouble to equip their Quality Assurance Officers with the required skills. This increases the importance of EQA to oversee the operations of HEls. He also identified commonly employed practices of IQA in various HE Institutions. These practices includes QA structures, student admission procedures, staff recruitment and development procedures, examination procedures, student's evaluation of courses and teaching effectiveness and institutional self-assessment. Regulators of EQA are also interested to see such practices are sufficient enough to provide quality education.

If HEls wants to become learning organizations to combat challenges they face, they should stop relying merely on being accredited externally but rather improve themselves internally (Fullanet al., 2015). From this study, it can be observed that EQA alone cannot suffice the excursion of $\mathrm{HEls}$ to becoming reputable learning organizations. Their internal total quality management is important in achieving the goal.

\section{External Quality Assurance}

A key function of External Quality Assurance is to stimulate change and improvement of teaching and learning processes in Higher Education Institutions. EQA acts as a bridge between universities and the government. Stensaker et al (2015) noted that EQA acts as governance tool that regulates the relationship between national authorities and Higher Education Institutions. Therefore EQA becomes a major platform for $\mathrm{HE}$ institutions to root their IQA guidelines. Going below the EQA requirements would mean deterring the relationship between the national authorities and the higher education institutions. Due to this background, different nations provide frameworks for EQA through their authorities.

In Tanzania for instance, the Commission for Universities (TCU) has put standards and guidelines that guide the daily operations of Higher Education in general. The TCU has provided quality assurance guidelines including the following:

1. Handbook for Standards and Guidelines for University Education in Tanzania
2. Guidelines for Overseas Education Students Recruitment Agencies

3. Principles and Guidelines for Evaluation of Foreign Awards and Recognition of Qualifications.

4. University Qualifications Framework (UQF)

Tanzania has also adopted other international quality assurance guidelines. These include the following four guidelines put forward by the InterUniversity Council for East Africa (IUCEA) Quality Assurance (IUCEA, 2010):

1. Volume 1: Guidelines for Self-Assessment at Program Level

2. Volume 2: Guidelines for External Assessment at Program Level

3. Volume 3: Guidelines for Self-Assessment at Institutional Level

4. Volume 4: Implementation of Quality Assurance System

TCU has been mandated by the government of Tanzania to recognize, approve, register and accredit Universities operating in the country. It further coordinates the proper functioning of all university institutions in Tanzania to ensure a harmonized higher education system in the country. The proper functioning of universities includes the quality assurance aspects. The government does so as to protect the interest of the public. For this reason, Higher Education Institutions have been required to establish $\mathrm{QA}$ Directorates to supervise the implementation of EQA and IQA. Regulators are expecting institutions to put in place strong internal QA procedures. Therefore, it is of no doubt that EQA practices impact higher education in one way or another. Higher education institutions should therefore understand and appreciate the magnitude of this impact and align their internal quality assurance practices within the EQA requirements.

\section{Impact of EQA in Higher Education}

A plethora of impact studies have been conducted in both developed and developing countries on the impact of EQA on delivery of quality university education. When assessing the impact or causality between variables, it needs a common understanding of what impact means. The causal relationship is that the event identified as 'cause' makes a difference (Pietsch, 2014). With this view of impact, the paper focuses on establishing what difference does EQA brings on HEls. As more and more countries globally have established their own national systems for EQA, issues related to the 
effectiveness and the efficiency of these initiatives have become more central (Massaro, 2010; Ulewitz, 2017). In this perspective, assessing the impact of EQA implies that it is the individual higher education institution that should be the focus of attention (Stensaker et al, 2015). Assertions by Stensaker (2015), positions the view that impact studies should focus on institutions as opposed to national systems, units and individuals. His view is widely opposed by Brenan (2005) who was of the view that impact studies should encompass individuals, units and national systems. The author carried out several studies in this area was of the view that impact studies should focus on finding out how key practices in HEls such as culture, attitude and procedures such as admission, examinations processing, recruitment, and promotions are impacted by EQA.

Although EQA practices have been viewed as imposition and prescription, bureaucratic practices which do not align with academic endeavor and that such practices negatively impacts personal and organizational behavior, there is a positive impact of EQA like increased transparency in decision making and improved teaching and learning quality (Cardoso et al, 2016). This is revealed by the fact that TCU closed down several universities in Tanzania for not implementing recommendations provided by the commission. To help explain why EQA recommendations were not being implemented effectively especially in private universities, hence lack of impact, Mgaiwa and Ishengoma (2017) established that the insufficiency of fiscal resources in private universities affects the compliance to quality assurance processes set by the TCU. This was found to be more acute in private universities than it is in public universities due to the fact that private universities have more financial obligations to be met by themselves unlike public universities which receive funds from the government. Hence, this increases non adherence of private universities to external quality assurance requirements.

Haapakorpi (2011) found that QA process brings excess work-load and insignificant benefits at the grass root. EQA adherence comes in with additional work load which demands institutions to allocate QA duties to members of staff. In some instances, this comes with additional cost for paying such personnel. Some of these extra work loads include preparation of accreditation documents and different submissions.
In Tanzania the TCU which is mandated to recognize, approve, register and accredit Universities operating in the country provides different guidelines so as to coordinate the proper functioning of all universities. Some of the EQA processes are: institutional self-assessment, internal audits and external examinations. Before the formation of TCU in 2005, the Government of Tanzania (GoT) commissioned quality control in higher education to Higher Education Accreditation Council (HEAC) which was formed in 1995. The gist of the HEAC was mainly to control quality of education offered by Private Universities. As such, HEAC registered and accredited all private universities in the country (Tanzania Commission for Universities, 2012). During that period, quality concerns were mainly for private universities. Public universities were believed to adhere to most quality requirements. In the search of high quality higher education, GoT found it relevant to regulate and control quality for both private and public universities in the country. It is for this reason TCU was established.

Since the establishment of TCU, Tanzania has seen major improvements in higher education ranging from infrastructures, quality staff, academic programs, admission criteria, students' assessment, awards recognition, etc. (URT, 2005). While there is limited empirical evidence to establish the level of quality conformity that the country has achieved through TCU, there is evidence that quality is still a problem in the country especially with Private Universities. This can be established by a series of deregistration of private universities due to nonconformity. In February 2016, for instance, TCU revoked the earlier approval that established two private universities (Kolumbia, 2016). Furthermore, in January 2020 TCU deregistered six universities and three campuses for quality issues including human resources, funds and poor infrastructures (Peter, 2020). All the nine institutions deregistered were private institutions. This justifies the place and role of TCU in quality control but also informs on the non-compliance with laws and regulations measures that have been put in place for quality assurance.

Higher education quality problem in Tanzania has also been connected to poor funding of education sector especially higher education sector. Komba (2017) established that higher education sector is currently being underfunded by the government. This trend does not only affect the issues of accessibility to and equity and equality in higher 
education but also impacts on the provision of quality higher education. The funding problem affects more private varsities as compared to public ones. A good example is on remuneration of staff. The government pays salaries for staff working in public universities while private universities use their internal funds to pay salaries, which limits them to expand infrastructures and attract competent staff. Therefore, apart from crucial role played by TCU, there is a need to support universities in complying with quality requirements through financial support.

Commenting on why EQA has less impact in HEls, Cardoso et al. (2016) conducted a study in Portuguese to determine main obstacles to quality as perceived by academics. The findings revealed that academics perceived that, the view of quality as culture and with its structural component design and functioning of institutional governance and management are the main obstacles to quality in higher education. He further observed that academics tend to have a poor knowledge about the structural frames that are embedded in governance and management which also limits HEls to realize the benefits from quality assurance practice. Similarly, Tezcan-Unal et al. (2018) found that most academics do not perceive that external quality assurance is a solution to their educational quality issues. This view may create resistance in implementation of EQA requirements and increase non adherence implications. It is therefore important, to provide enough knowledge on governance, management and the value of EQA practices to academics in HEls. This is crucial for smooth implementation of quality assurance practices.

Tezcan-Unal (2018) conducted a study to explore whether external quality assurance practices could influence higher education institutions in becoming a reputable learning organization. Using a case study they recommended that higher education institutions should make use of external quality assurance processes to become reputable learning organization. They further established that an approach that places learning at the core of quality seems to be necessary. Notably, Okogba (2016) found that HEls may benefit from EQA practices if they are willing to turn the demanding processes into a sustainable growth opportunity. This tells us that EQA is quite demanding, but however if taken serious, institutions will enjoy the benefits and an opportunity to grow sustainably.
Quality assurance ensures higher education institutions provide best service to their customers. If well utilized, external quality assurance practices can help universities to go beyond 'good enough.' This means that universities will be able to exceed stakeholders' expectations (Fullan et al., 2015).

\section{Conclusions and Recommendations}

This part gives the conclusions of the study and comes up with recommendations.

\section{Conclusions}

External quality assurance impacts universities positively and negatively. While some of these impacts like increased cost of operations related to adherence of EQA requirements are negative, some positive impacts include increased enrolment, quality output (meeting stakeholders' goals and expectations) and good internal quality assurance practices. While EQA is quite demanding, if taken serious, institutions will enjoy the benefits and an opportunity to grow sustainably. The implementation of EQA practices in HEls requires willingness and management support. For quality assurance to be a culture, it should involve everyone in the Higher Learning Institutions. While there exists resistance to EQA by some academics as they do not appreciate its impact on the quality of Higher Education, if they get involved in the whole process, such resistance will be reduced.

\section{Recommendations}

The authors give the following recommendations:

1. External quality assurance practices should align with globalization pace which creates new challenges and puts higher education quality in scrutiny. Moreover, quality assurance process should be student focused. For this case, students' feedback on the service they receive from higher learning institutions should form part of the requirements for Accreditation purpose.

2. More involvement of Academics on quality issues and practices in needed. This is due to the fact that the effectiveness of $Q A$ schemes is dependent on academics' acceptance of the process.

3. HEls should equip their quality assurance staff with the necessary skills for effective performance.

4. EQA Bodies through their government should revisit financial implications/ cost borne on adherence to some EQA requirements. Whenever possible the 
government should subsidize some of these costs.

5. EQA alone cannot suffice the need of HEls to becoming reputable learning institutions. Therefore they should focus on Total Quality Management Practice.

\section{Reference}

Cardoso, S., Rosa, M. J., \& Stensaker, B. (2016). Why is quality in higher education not achieved? The view of academics. Assessment \& evaluation in higher education, 41(6), 950965.

Brennan, L. (2005). Integrating work-based learning into higher education. Bolton, University Vocational Awards Council.

Fullan, M., Rincón-Gallardo, S., \& Hargreaves, A. (2015). Professional capital as accountability. education policy analysis archives, 23, 15.

Haapakorpi, A. (2011). Quality assurance processes in Finnish universities: Direct and indirect outcomes and organisational conditions. Quality in Higher Education, 17(1), 69-81.

IUCEA, (2010). A Road map to Quality Hand book for Quality Assurance in Higher Education. German Rectors Conference, Vol 4.

Kolumbia, L. (2016). Tanzania: TCU Revokes Approval to Establish Two Colleges of St. Joseph University. The Citcizen.

Komba, S. C. (2017). Issues on Financing Higher Education in Tanzania. In The Future of Accessibility in International Higher Education (pp. 125-138). IGI Global.

Liu, S. Q., \& Mattila, A. S. (2015). “I want to help" versus "I am just mad" how affective commitment influences customer feedback decisions. Cornell Hospitality Quarterly, 56(2), 213-222.

Martin, M. (2018). Internal Quality Assurance: Enhancing higher education quality and graduate employability.

Massaro, V. (2010). Cui bono? The relevance and impact of quality assurance. Journal of Higher Education Policy and Management, 32(1), 17-26.

Mgaiwa, S. J., \& Ishengoma, J. M. (2017). Institutional constraints affecting quality assurance processes in Tanzania's private universities. Journal of Higher Education in Africa/Revue de l'enseignement supérieur en Afrique, 15(1), 57-67.

Okae-Adjei, S. (2016). Internal quality assurance in higher education institutions: The case of some selected Ghanaian polytechnics. European Journal of Research in Social Sciences, 4(8).

Okogbaa, V. (2016). Quality in Higher Education: The Need for Feedback from Students. Journal of Education and Practice, 7(32), 139-143.

Parri, J. (2006). Quality in Higher Education. Vadyba Management 2 (11), 107-111.

Peter, F. (2020). Tanzania: TCU deregisters six Varsities, three Campuses citing quality. The Guardian.

Pietsch, W. (2014). The structure of causal evidence based on eliminative induction. Topoi, 33(2), 421-435.

Ryan, T. (2015). Quality assurance in higher education: A review of literature. Higher learning research communications, 5(4), 1.

Smidt, H. (2015). European quality assurance-A European higher education area success story [overview paper]. In The European Higher Education Area (pp. 625-637). Springer, Cham.

Stensaker, B., \& Leiber, T. (2015). Assessing the organisational impact of external quality assurance: hypothesising key dimensions and mechanisms. Quality in Higher Education, 21(3), 328-342.

Tanzania Commission for Universities (2012).

Background and Core functions https://www.tcu.go.tz/?q=node/2.

Retrieved $10^{\text {th }}$ September,2020.

Tezcan-Unal, B., Winston, K., \& Qualter, A. (2018). Learning-oriented quality assurance in higher education institutions. Quality in Higher Education, 24(3), 221-237.

Ulewitz, R. (2017). The role of stakeholders in quality assurance in higher education. Human Resources Management \& Ergonomics, 11(1).

United Republic of Tanzania (2005). Universities Act. Dar es Salaam: Government Printer. 